\title{
Sodium and potassium excretion in an adult Caribbean population of African descent with a high burden of cardiovascular disease
}

Rachel M. Harris ${ }^{1 *}$, Angela M. C. Rose ${ }^{1}$, lan R. Hambleton ${ }^{1}$, Christina Howitt ${ }^{1}$, Nita G. Forouhi ${ }^{2}$, Anselm J. M. Hennis ${ }^{1}$, T. Alafia Samuels ${ }^{1}$ and Nigel Unwin ${ }^{2}$

\begin{abstract}
Background: High sodium diets with inadequate potassium and high sodium-to-potassium ratios are a known determinant of hypertension and cardiovascular disease (CVD). The Caribbean island of Barbados has a high prevalence of hypertension and mortality from CVD. Our objectives were to estimate sodium and potassium excretion, to compare estimated levels with recommended intakes and to identify the main food sources of sodium in Barbadian adults.
\end{abstract}

Methods: A sub-sample ( $n=364 ; 25-64$ years) was randomly selected from the representative population-based Health of the Nation cross-sectional study $(n=1234)$, in 2012-13. A single 24-h urine sample was collected from each participant, following a strictly applied protocol designed to reject incomplete samples, for the measurement of sodium and potassium excretion (in $\mathrm{mg}$ ), which were used as proxy estimates of dietary intake. In addition, sensitivity analyses based on estimated completeness of urine collection from urine creatinine values were undertaken. Multiple linear regression was used to examine differences in sodium and potassium excretion, and the sodium-to-potassium ratio, by age, sex and educational level. Two 24-h recalls were used to identify the main dietary sources of sodium. All analyses were weighted for the survey design.

Results: Mean sodium excretion was 2656 (2488-2824) mg/day, with 67\% (62-73\%) exceeding the World Health Organization (WHO) recommended limit of $2000 \mathrm{mg} / \mathrm{d}$. Mean potassium excretion was 1469 (1395-1542) mg/d; < $0.5 \%$ met recommended minimum intake levels. Mean sodium-to-potassium ratio was 2.0 (1.9-2.1); not one participant had a ratio that met WHO recommendations. Higher potassium intake and lower sodium-to-potassium ratio were independently associated with age and tertiary education. Sensitivity analyses based on urine creatinine values did not notably alter these findings.

Conclusions: In this first nationally representative study with objective assessment of sodium and potassium excretion in a Caribbean population in over 20 years, levels of sodium intake were high, and potassium intake was low. Younger age and lower educational level were associated with the highest sodium-to-potassium ratios. These findings provide baseline values for planning future policy interventions for non-communicable disease prevention.

Keywords: 24-h urine collection, Adult, Barbados, Diet, Excretion, Potassium, Salt, Sodium

\footnotetext{
* Correspondence: rachel.harris@mycavehill.uwi.edu

${ }^{1}$ The George Alleyne Chronic Disease Research Centre, Caribbean Institute for Health Research, The University of the West Indies, Bridgetown, Barbados Full list of author information is available at the end of the article
}

(c) The Author(s). 2018 Open Access This article is distributed under the terms of the Creative Commons Attribution 4.0 International License (http://creativecommons.org/licenses/by/4.0/), which permits unrestricted use, distribution, and reproduction in any medium, provided you give appropriate credit to the original author(s) and the source, provide a link to the Creative Commons license, and indicate if changes were made. The Creative Commons Public Domain Dedication waiver (http://creativecommons.org/publicdomain/zero/1.0/) applies to the data made available in this article, unless otherwise stated. 


\section{Background}

Globally the consumption of sodium exceeds recommended levels [1]; with the main contributor being salt (sodium chloride), which is ubiquitous in the food supply [2]. The World Health Organization (WHO) has set a target of a 30\% reduction in mean population salt intake by 2025 (compared with 2010) and the goal of $400 \mathrm{~g} /$ day per individual of fruit and vegetables (potassium rich sources), for the prevention of chronic non-communicable diseases (NCDs). In addition, WHO recommends adults consume $<2000 \mathrm{mg}$ sodium and $>$ $3500 \mathrm{mg}$ potassium per day [3, 4]. High sodium diets with inadequate potassium, and high sodium to potassium (Na:K) ratios, are known to be predictors of raised blood pressure (BP) and cardiovascular disease (CVD) mortality [5, 6].

Barbados is an independent, densely populated, Caribbean island (277,821 persons, land area 166 sq. miles), 94\% of whose population is of African origin [7]. There is a high prevalence of hypertension (41\%) among Barbadian adults ( $\geq$ 25 yrs) [8], and $80 \%$ of deaths are attributed to NCDs, with $24 \%$ of deaths in women and $29 \%$ in men being due to CVD, predominantly stroke and coronary artery disease [9]. Data on dietary sodium and potassium intake in the Barbadian population are scarce. The collection of a timed $24 \mathrm{~h}$ urine sample for the measurement of sodium and potassium excretion, as proxies for dietary intake, is the method of choice for assessing population levels [10-12], with approximately $85-90 \%$ of dietary sodium and $>85 \%$ of dietary potassium being excreted in the urine $[12,13]$. This methodology was last used in Barbados over 20 years ago [14, 15]. However, neither of these two previous studies used representative population-based samples. In fact, as far as we are aware there has not been a population- based study of sodium excretion in the whole of the Caribbean for over 20 years [16].

Our aim in this study was to estimate urinary sodium and potassium excretion in a representative population-based sample of Barbadian adults, and to identify the major dietary sources of sodium. The findings from this study will be used to inform, and provide a baseline for, interventions aimed at improving diet to prevent NCDs in Barbados, and will be of interest throughout the Caribbean.

\section{Methods}

\section{Study population}

The study population was a sub-sample of the Barbados Health of the Nation (HotN) cross-sectional study, which recruited a representative sample of adults aged $\geq 25$ years ( $n=1234)$. Details of the sampling, recruitment and data collection methods in the HotN study have been published elsewhere [8]. From this study, a sample of 441 adults aged 25-64 years was selected, stratified by sex and age-group (25-44 and 45-64 years), with the aim of recruiting at least 100 participants in each group. This sample size was based on the consideration that to detect a difference of $1 \mathrm{~g}$ in salt excretion per day (equivalent to $17 \mathrm{mmol}$ or $390 \mathrm{mg}$ sodium) between two groups (with alpha of 0.05 and power of 0.8 ), and assuming a standard deviation in both groups of $50 \mathrm{mmol}$ of sodium (based on WHO guidance), a minimum of 98 participants per group is required [10].

Participants were eligible if they met the following criteria: no reported history of renal, heart or liver disease or stroke; and had not started diuretics in the previous 2 weeks. Pregnant and lactating women were excluded because of their unique nutritional requirements.

\section{Data collection}

After pilot testing field staff were trained in standardized methods and assessed on their competence and adherence to the study protocol, which was checked throughout the period of data collection. Two face-to-face interviews were held in participants' homes, between June 2012 and November 2013. Participants were seen within 3 months of their HotN interview. Data on age, sex and educational level were collected, by questionnaire. Education was used as a marker of socioeconomic position, grouped into two categories: less than tertiary education and tertiary education. Tertiary education was defined as post-secondary education including college, vocational and university training.

\section{4-h urine collection}

Sodium and potassium excretion were measured from a single timed 24-h urine collection, which is acceptable for estimating values in population-based studies [12, 17, 18]. Internationally recommended standard procedures developed by the WHO/PAHO Regional Expert Group for Cardiovascular Disease Prevention were followed [10]. At the first interview, equipment, written instructions and a simplified chart detailing the 24-h urine collection method were given and a convenient day for the urine collection identified. To increase compliance with the strict protocol, a diary in which the timing of the urine collection, any missed urine voids, strenuous activity, illness (specifically vomiting or diarrhoea) and any medication taken during the collection period were recorded.

The urine collection commenced by discarding the first urine void at the beginning of the collection period. This point was noted as the start of the 24-h collection. All urine was then collected from that point onwards until the final void on the following day, at the corresponding $24 \mathrm{~h}$ finish time. Urine samples were kept in refrigerated conditions or in a cool, dark place on ice until collection on the day of completion. Transportation to the laboratory was undertaken using insulated bags containing ice packs. Urine samples were analysed using the Roche Hitachi Cobas C311 system ion selective electrode (Roche Diagnostics Ltd., Charles Ave, W. Sussex, RH15 9RY, UK) for sodium and potassium at a laboratory certified by the College of American Pathologists. Creatinine concentrations were assessed by the Roche Hitachi Cobas C311 analyser (Roche 
Diagnostics Ltd., Charles Ave, W. Sussex, RH15 9RY, UK) using the Jaffe's reaction with alkaline picrate.

Completeness of urine collection was assessed through volume, adherence to protocol and urinary creatinine. In accordance with guidance from the PAHO, para-aminobenzoic acid (PABA) was not used [10]. Urine samples were excluded if the urine volume was $<500 \mathrm{ml}$ or $>5000 \mathrm{ml}$, timing of collection fell outside the $20-28 \mathrm{~h}$ period or the participant reported missing more than one urine void. If participants reported missing more than one void, a second 24-h urine collection was requested.

If the duration of the collection was not exactly $24 \mathrm{~h}$ (but within 20-28 h), urinary sodium, potassium, creatinine, and total volume were normalized to a $24 \mathrm{~h}$ period. Urinary creatinine excretion is related to lean body mass and to diet but has substantial intra-individual and inter-individual variation [17]. Nonetheless, using creatinine levels to exclude individuals with presumed incomplete urine collection provides a useful, if imperfect, approach to sensitivity analysis. We used two approaches. Firstly, we excluded individuals if their total $24 \mathrm{~h}$ creatinine excretion was less than $4 \mathrm{mmol}(455 \mathrm{mg})$ in women and less than $6 \mathrm{mmol}(682 \mathrm{mg})$ in men. This is in line with recent population-based studies assessing sodium excretion in South Africa [19] and the Netherlands [20]. In addition, we calculated expected creatinine excretion (in mg per day) using the formulae of Joossens and Goboers [21] i.e. $24 \mathrm{x}$ body weight $(\mathrm{Kg})$ in men, and $21 \mathrm{x}$ body weight in women. We then restricted our analyses to those individuals whose creatinine was $\geq 0.7$ of predicted. This cut-point is based on a recent systematic review [22] that concluded this provided, on the basis of the current limited evidence, the most sensitive approach to excluding incomplete urine samples.

\section{Dietary data}

Two non-consecutive, interviewer-administered, 24-h dietary recalls were collected from each participant with the aim to capture the participants' diet on one week day and one weekend day. The systematic probing of all foods and beverages consumed in the previous $24 \mathrm{~h}$, including supplements, were detailed using the United States Department of Agriculture (USDA) multi-pass method [23]. Information on serving sizes and portions consumed in one sitting were estimated using three-dimensional Nasco food models (Nasco Company, 901 Jamesville Ave, Fort Atkinson, Wisconsin 53,538, USA), standard measuring cups and household utensils. The timing, food source, frequency of consumption, cooking method, seasoning use and recipes were documented.

Listed food items were coded and recorded portions converted into grams. These data were then entered into the nutrition software, Nutribase Pro (version 9, Cybersoft Inc., 2016 E. Muirwood Drive, Phoenix, Arizona, USA). Standardized traditional Barbadian recipes, which were analyzed using the weighed recipe approach, [24] were added to the
United States Department of Agriculture (USDA) and Canadian food composition database making this software more culturally appropriate. Foods were placed into food categories based on previous work done in Barbados [25].

\section{Statistics}

The data were weighted to account for the clustered sampling design, to adjust for non-response and to reflect the age and sex distribution of the underlying Barbadian population based on the Barbados Census 2010 [7]. A series of linear regression analyses were used to explore the contribution of age, sex and educational level on sodium and potassium excretion. The appropriateness of using linear regression was determined by examining and confirming the normal distribution of the residuals of the linear regression models. We present $95 \%$ confidence intervals $(95 \%$ $\mathrm{CI})$, along with exact $p$ values where appropriate. Statistical significance was accepted as $p<0.05$.

Cut-points for sodium and potassium intake were based on guidance from two agencies: the American Heart Association (AHA) recommends a sodium intake of no more than $1500 \mathrm{mg} / \mathrm{d}$ for people of African origin and no more than $2300 \mathrm{mg} / \mathrm{d}$ of sodium and a potassium intake of at least $4700 \mathrm{mg} / \mathrm{d}$ for all participants [26]; WHO recommends a sodium intake of no more than $2000 \mathrm{mg} / \mathrm{d}$, and a potassium intake of at least $3500 \mathrm{mg} / \mathrm{d}$ [27]. We calculated the urinary Na:K ratio. Based on the above targets, a Na:K ratio of approximately 0.49 and 0.57 is recommended by the AHA and WHO respectively. As described in the results, no individual had a ratio that met the AHA or WHO guidance, and therefore we also used a pragmatic cut-point for the ratio of $\leq 1$ i.e. where the potassium excretion (in $\mathrm{mg}$ ) is equal to or greater than the sodium excretion.

All statistical analyses were performed using Stata software package (V.12, Stata Corp, College Station, Texas, USA).

\section{Results}

A total of 441 participants were selected from the HotN study sample and assessed for eligibility, of these 368 $(83 \%)$ consented to take part. Four urine samples were deemed incomplete on the basis of total sample volume and excluded. The characteristics of participants in the final study sample of 364 are shown in Table 1. Using WHO body mass index (BMI) cut-points of 25 and $30 \mathrm{~kg} / \mathrm{m}^{2}$ to classify overweight and obesity, respectively, $66 \%$ of participants were classified as overweight or obese and $36 \%$ as obese ( $25 \%$ of men, $46 \%$ of women were obese). The prevalence of hypertension was $34 \%$, being similar for both sexes. An estimated 9\% self-reported a diagnosis of diabetes whilst $13 \%$ of the sample were diagnosed with diabetes presenting with a fasting blood glucose level of $\geq 7.0 \mathrm{mmol} / \mathrm{l}$.

In Table 2 the mean values (with $95 \% \mathrm{CI}$ ) of sodium and potassium excretion and Na:K ratio, are shown by age and 
Table 1 Characteristics of the Barbados National Salt study population (2012-2013). Unless indicated otherwise, the figures in parentheses are $95 \%$ confidence intervals

\begin{tabular}{|c|c|c|c|}
\hline & Women $(n=203)$ & Men $(n=161)$ & Overall $(N=364)$ \\
\hline \multicolumn{4}{|l|}{ Number (\%) by age (years) } \\
\hline $25-44$ & $90(46.0)$ & $76(49.1)$ & $16(47.8)$ \\
\hline $45-64$ & $113(54.0)$ & $85(50.9)$ & $198(52.2)$ \\
\hline \multicolumn{4}{|l|}{ Number (\%) by education } \\
\hline$<$ Tertiary $^{\mathrm{a}}$ & $127(77.9)$ & $99(76.3)$ & $226(77.2)$ \\
\hline Tertiary $^{\mathrm{a}}$ & $76(22.1)$ & $62(23.7)$ & $138(22.8)$ \\
\hline \multicolumn{4}{|l|}{ Anthropometry } \\
\hline Mean BMI $\left(\mathrm{Kg} / \mathrm{m}^{2}\right)$ & $30.3(29.0,31.6)$ & $27.1(26.0,28.2)$ & $28.7(27.9,29.6)$ \\
\hline Mean waist circ $(\mathrm{cm})$ & $94.7(91.9,97.4)$ & $92.4(89.7,95.1)$ & $93.6(91.9,95.2)$ \\
\hline$\%$ overweight (BMl $\geq 25$ ) & $73.9(64.1,81.8)$ & $57.9(47.2,67.9)$ & $66.0(58.4,72.9)$ \\
\hline$\%$ obese (BMI $\geq 30$ ) & $46.4(38.4,54.6)$ & $25.3(19.0,32.8)$ & $36.0(30.8,41.5)$ \\
\hline \multicolumn{4}{|l|}{ Blood pressure } \\
\hline Systolic BP (mm Hg) & $124.4(121.6,127.2)$ & $130.5(127.4,133.7)$ & $127.3(125.3,129.4)$ \\
\hline Diastolic BP (mm Hg) & $78.1(76.1,80.0)$ & $79.5(77.1,81.8)$ & $78.7(77.3,80.2)$ \\
\hline$\%$ reported hypertension & $25.8(17.8,36.0)$ & $14.4(9.6,21.0)$ & $20.4(15.5,26.3)$ \\
\hline$\%$ total hypertension & $35.5(27.5,44.4)$ & $32.7(23.2,43.8)$ & $34.1(27.7,41.2)$ \\
\hline \multicolumn{4}{|l|}{ Glucose } \\
\hline Fasting (mmol/l) & $5.5(5.2,5.8)$ & $5.4(5.2,5.6)$ & $5.4(5.3,5.6)$ \\
\hline$\%$ reported diabetes & $9.9(5.7,16.5)$ & $9.0(5.0,15.6)$ & $9.4(6.6,13.3)$ \\
\hline$\%$ all diabetes & $15.1(9.8,22.5)$ & $10.9(6.1,18.7)$ & $13.1(9.6,17.6)$ \\
\hline
\end{tabular}

${ }^{a}$ Tertiary refers to all post-secondary school education, including technical and vocational training as well as university course

Percentages are weighted to compensate for unequal probabilities of selection (selecting one individual from household) and for non-response

sex. Mean sodium excretion was $2656 \mathrm{mg} / \mathrm{d}$ (equivalent to $6.75 \mathrm{~g}$ salt/d); and significantly higher in men compared to women (difference $423 \mathrm{mg} / \mathrm{d} ; 95 \%$ CI 86-760; $p=0.015$ ). Mean potassium excretion was $1469 \mathrm{mg} / \mathrm{d}$, being non-significantly higher in men $(1558 \mathrm{mg} / \mathrm{d})$ than women $(1386 \mathrm{mg} / \mathrm{d})$; all participants of both sexes and across all age groups were below the minimum recommended potassium intake for adults of $4700 \mathrm{mg} / \mathrm{d}$ (the AHA recommended level); with only two participants exceeding

Table 2 Twenty-four hour urinary sodium and potassium, and the sodium-to-potassium ratio, by age and sex, Barbados (2012-2013)

\begin{tabular}{llll}
\hline & Sodium $(\mathrm{mg})$ & Potassium $(\mathrm{mg})$ & Na:K ratio \\
\hline Women & & & \\
25-44 years & $2596(2224,2968)$ & $1264(1141,1386)$ & $2.1(1.9,2.3)$ \\
$45-64$ years & $2302(2075,2530)$ & $1515(1356,1673)$ & $1.7(1.5,1.8)$ \\
$\begin{array}{l}\text { Total } \\
\text { Men }\end{array}$ & $2453(2195,2710)$ & $1386(1275,1497)$ & $1.9(1.8,2.0)$ \\
25-44 years & $2971(2681,3261)$ & $1507(1372,1642)$ & $2.1(2.0,2.3)$ \\
$45-64$ years & $2768(2489,3047)$ & $1617(1421,1812)$ & $2.0(1.7,2.3)$ \\
Total & $2876(2665,3087)$ & $1558(1442,1674)$ & $2.1(1.9,2.3)$ \\
Men and women & & & \\
25-44 years & $2780(2544,3015)$ & $1382(1290,1475)$ & $2.1(2.0,2.3)$ \\
$45-64$ years & $2521(2322,2721)$ & $1563(1440,1684)$ & $1.8(1.7,2.0)$ \\
Total & $2656(2488,2824)$ & $1469(1395,1542)$ & $2.0(1.9,2.1)$ \\
\hline
\end{tabular}

Figures are means (95\% confidence intervals)
$3500 \mathrm{mg} / \mathrm{d}$ (the WHO recommended level). The mean $\mathrm{Na}: \mathrm{K}$ ratio was 2.0. The lowest ratio was 0.79 , and thus no participant had a ratio in line with WHO and AHA recommended relative intakes of sodium and potassium. The ratio was greater than 1 for $87 \%$ of the population.

The percentages (with 95\% CI) of the population consuming more than recommended levels of sodium, using the AHA and WHO guidelines are shown in Figs. 1 and 2. The AHA upper limit of $1500 \mathrm{mg}$ was exceeded by $79 \%$ women and $89 \%$ men. The WHO upper limit of $2000 \mathrm{mg} /$ $\mathrm{d}$ (equivalent to $5 \mathrm{~g}$ of salt) was exceeded by $68 \%$ of the population. Although confidence intervals are broad, there are higher proportions exceeding sodium intake guidelines in those with tertiary education compared with those with less than tertiary education. The proportion of participants exceeding a $\mathrm{Na}: \mathrm{K}$ ratio of 1 was higher in men, also in the younger age group (25-44 years) and in those participants with a primary or secondary education only.

The results of multiple linear regression are shown in Table 3. Male sex $(p<0.014)$, but neither age nor education, was significantly related to sodium excretion. There was a significant positive association between potassium excretion and age $(p=0.002)$; as well as between potassium excretion and educational level $(p=0.024)$. There was a significant negative association between the Na:K ratio and age $(\mathrm{p}=0.002)$; as well as educational level $(p=0.039)$. Further adjustment for BMI (data not shown) made little difference to these findings. 


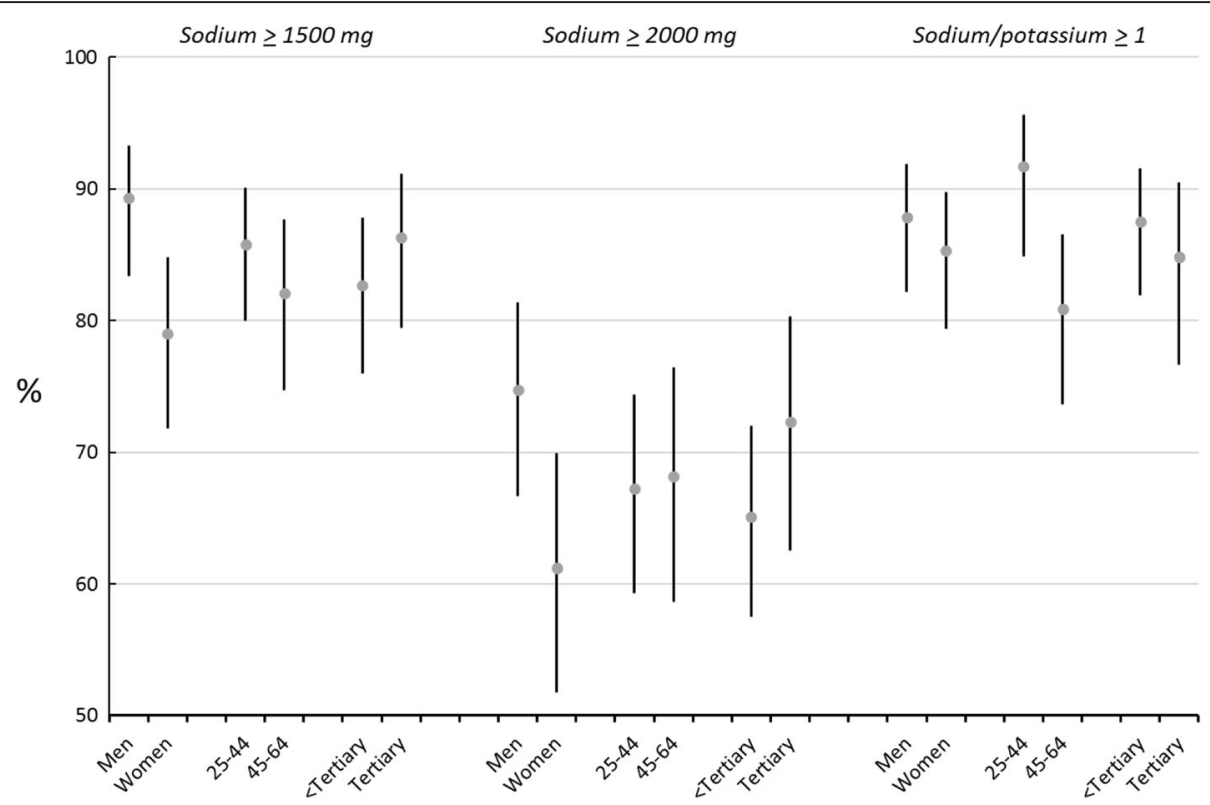

Fig. 1 Percentages (95\% Cls) exceeding recommended daily levels of sodium excretion and a sodium-to-potassium ratio > 1, by sex, age group and educational level in Barbados (2012-2013).

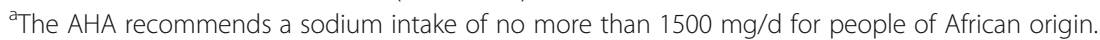

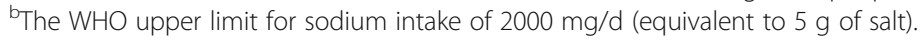

${ }^{\mathrm{C} T e r t i a r y ~ r e f e r s ~ t o ~ a l l ~ p o s t-s e c o n d a r y ~ s c h o o l ~ e d u c a t i o n, ~ i n c l u d i n g ~ t e c h n i c a l ~ a n d ~ v o c a t i o n a l ~ t r a i n i n g ~ a n d ~ u n i v e r s i t y ~ c o u r s e s ~}$

Sensitivity analyses were performed, using urinary creatinine to assess for sample completeness. Firstly, restricting to those with $\geq 4 \mathrm{mmol}$ (women) and $6 \mathrm{mmol}$ (men) creatinine in their urine $(n=317)$ and then restricting to those with a creatinine index of $\geq 0.7(n=184)$. In both sensitivity analyses, the mean estimates of sodium and potassium excretion were modestly higher, but the $95 \%$ CI from these restricted analyses and those of the whole sample overlapped greatly (as shown in Table 2 ). The Na:K ratio essentially remained unchanged (Tables 5 and 6 in Appendix).

Food groups previously described for Barbados were used to classify foods [25]. The top three food groups for sodium were rice, poultry and bread. (Table 4) Five food items contributed over one-quarter of total sodium dietary intake (28.9\%), similar for both sexes. These foods were any bread $(9.2 \%)$, rice and peas (6.2\%), baked chicken (4.9\%), macaroni pie $(4.3 \%)$, white rice (4.3\%) (data not shown). No statistically significant differences were found in sodium intake sources for either the top 10 food groups or top 10 food items by age, sex or education.

\section{Discussion}

In this nationally representative, population-based study in Barbados, a high prevalence of CVD risk factors (hypertension: $34 \%$, diabetes: $13 \%$, obesity: $36 \%$ ) co-exist with high intakes of sodium and inadequate potassium intake. The mean daily sodium excretion exceeded the daily recommendations for both sexes, in all age categories. The AHA recommends an upper limit of $1500 \mathrm{mg} / \mathrm{d}$ of sodium for populations of
African descent; in our study $79 \%$ of women and $89 \%$ of men exceeded this upper limit. The WHO upper limit of $2000 \mathrm{mg} / \mathrm{d}$ for sodium was exceeded by $68 \%$. Potassium excretion was low, with all participants irrespective of age and sex falling below the adult AHA $(4700 \mathrm{mg} / \mathrm{d})$ recommendation and the vast majority (>99\%) below the WHO $(3500 \mathrm{mg} / \mathrm{d})$ level. Linear regression analyses indicated that potassium intake was higher in persons aged 45-64 years compared with participants 25-44 years and for those of higher education. The WHO recommends a Na:K ratio of $<$ 0.57; if the AHA guidelines are met the ratio would be $<0.32$ (1500 divided by 4700). The ratio of $\mathrm{Na}: \mathrm{K}$ is a critical factor in hypertension. Higher Na:K ratios have been associated with diets high in processed foods, and thus high in sodium, and low in potassium $[28,29]$.

Within the Caribbean region there have been no recent population-based measurements of sodium excretion using the 'gold standard' method of 24-h urinary collection. Only three studies have been conducted within the last 25 years, none of which used a nationally representative sample [16]. The 2010 global estimated mean sodium excretion in adults was 3950 (3890-4010) $\mathrm{mg} /$ day; being higher in men than that in women: $4140(4040-4230)$ vs $3770(3690-3850)$ $\mathrm{mg} /$ day, respectively, higher than the mean estimates found in our study [16]. However, our findings are comparable to those described in other parts of the Caribbean, albeit over 20 years ago. For example, the estimated mean sodium excretion levels were $1920 \mathrm{mg} / \mathrm{d}$ and $2930 \mathrm{mg} / \mathrm{d}$ for Jamaica and Trinidad respectively [16]. 


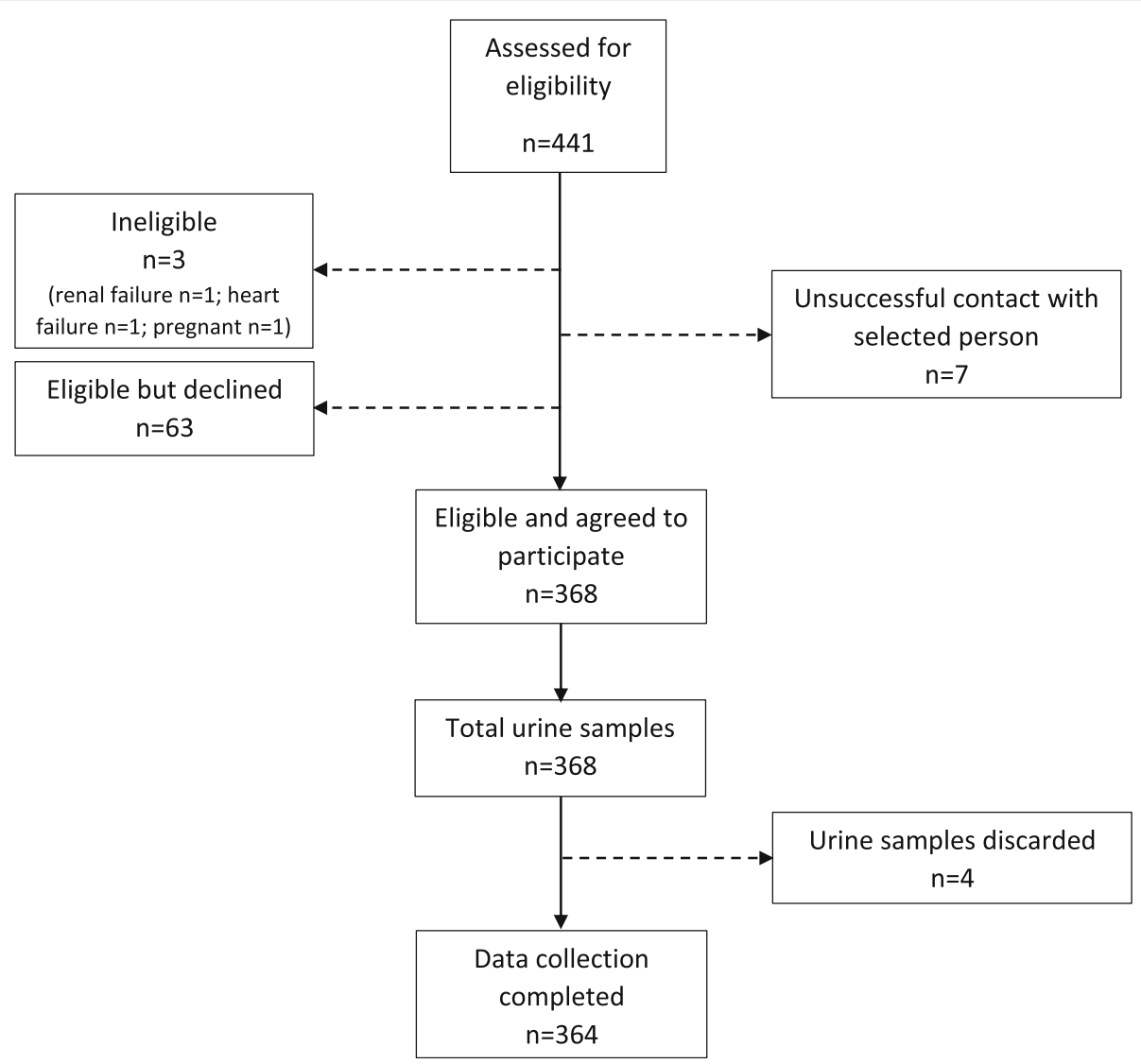

Fig. 2 Participant flow chart

A limited number of studies have used the 24-h urine collection method to evaluate both sodium and potassium excretion concurrently. Recent work in South Africa, estimated the median sodium and potassium excretion at $2827 \mathrm{mg} / \mathrm{d}$ and $1307 \mathrm{mg} / \mathrm{d}$, respectively. The majority (92.8\%) of the population did not meet the WHO

Table 3 Age, sex and educational level ${ }^{\mathrm{a}}$ as predictors of sodium and potassium excretion, in multiple linear regression

\begin{tabular}{lll}
\hline & Beta $(95 \% \mathrm{Cls})$ & $P$ value \\
\hline Sodium (mg per day) & $-7.4(-26.3,11.4)$ & 0.431 \\
Age (years) & $428.0(91.3,764.6)$ & 0.014 \\
Sex (male vs. female) & $-24.7(-394.1,344.7)$ & 0.893 \\
Education (tertiary vs. less than) & $13.3(5.3,21.3)$ & \\
Potassium (mg per day) & $162.3(-11.8,336.4)$ & 0.002 \\
Age (years) & $183.5(24.9,342.1)$ & 0.067 \\
Sex (male vs. female) & & 0.024 \\
Education (tertiary vs. less than) & $-0.032(-0.052,-0.012)$ & 0.002 \\
Sodium-to-potassium ratio & $0.331(-0.019,0.682)$ & 0.063 \\
Age (years) & $-0.427(-0.832,-0.022)$ & 0.039 \\
\hline Sex (male vs. female) &
\end{tabular}

${ }^{a}$ Analyses by age, sex and educational level entered together recommended daily potassium intake of $3500 \mathrm{mg} / \mathrm{d}$, and $65.6 \%$ consumed more than $2000 \mathrm{mg} / \mathrm{d}$ sodium. The median Na:K ratio was 3.5. Overall, findings of this South African study are similar to ours [30]. In China the mean 24-h urinary sodium excretion level was substantially higher $(5336 \mathrm{mg} / \mathrm{d})$ whereas potassium levels were comparable $(1591 \mathrm{mg})$ to our estimates in Barbados. Males were also found to have higher urinary sodium excretion

Table 4 Top 10 food group sources of dietary sodium for men and women, by \% sodium

\begin{tabular}{lll}
\hline Food group & Frequency $^{\mathrm{a}}(\%)$ & \% Sodium $(95 \% \mathrm{Cl})$ \\
\hline Rice & $389(4.6)$ & $13.4(13.4,13.5)$ \\
Poultry & $487(5.8)$ & $13.0(12.9,13.0)$ \\
Bread & $472(5.6)$ & $12.3(12.2,12.3)$ \\
Fish & $339(4.0)$ & $6.9(6.9,6.9)$ \\
Processed meats & $208(2.5)$ & $6.3(6.3,6.4)$ \\
Cakes, sweet breads & $278(3.3)$ & $6.1(6.0,6.1)$ \\
Pasta & $187(2.2)$ & $5.5(5.5,5.5)$ \\
Vegetables & $589(7.0)$ & $5.5(5.5,5.5)$ \\
Ground provisions & $427(5.1)$ & $5.3(5.3,5.3)$ \\
Red meat & $222(2.6)$ & $5.2(5.1,5.2)$
\end{tabular}

${ }^{\mathrm{a} F r e q u e n c y: ~ n u m b e r ~ o f ~ t i m e s ~ f o o d ~ g r o u p ~ w a s ~ r e p o r t e d, ~ a s ~ a ~ p e r c e n t a g e ~ o f ~ a l l ~}$ food items reported 
than females. The mean Na:K ratio was 6.7 [31]. Our work is to the best of our knowledge, the first in the Caribbean to assess sodium and potassium excretion concurrently.

Our study had several strengths. We used a representative sample, with $83 \%$ of those invited participating. Our use of 24-h urine collection, the clinical "gold standard" method, provided an objective measurement of electrolyte excretion as a proxy for dietary intake. We followed strict protocols and comprehensive instruction to ensure completeness of urine collection as laid out in the WHO guidelines [10], similar to other large population-based studies [32, 33]. In addition to the application of the strict urine collection protocol, the sensitivity analyses using urinary creatinine measurements provided reassurance that population mean values are not significantly biased by incomplete urine collection. By recording two non-consecutive dietary recalls, we obtained a more representative picture of an individual's usual diet.

A limitation of our study is the use of a single 24-h urine collection per individual. This is a valid and reliable approach to estimating population levels of sodium and potassium intake [10-13] but is poor at an individual level because of marked day to day variation [12]. In addition, our sample size was relatively small. With the limited resources available, we had the power to detect approximately a $1 \mathrm{~g}$ salt difference between two subgroups, such as males versus females, younger (25-44 years) and older (45-65 years) age groups and higher versus lower education. However, given the single 24-h urine collection per individual and the relatively small sample size our study was not designed to evaluate the relationships between sodium and potassium intake and blood pressure.

The study methods rely on the abilities of individuals to completely and accurately collect their urine over $24 \mathrm{~h}$. The robustness of our findings was tested through sensitivity analyses using urinary creatinine levels to estimate whether complete urine collection was achieved. This is an imperfect approach for several reasons, including marked day to day intra and inter individual variability in creatinine excretion [17, 34], and that the equations used to estimate expected excretion have not been validated in our population. We used two complementary approaches, one that excluded $13 \%$ of our sample and the other excluding almost half. The latter was based on a creatinine cut off based on a recent systematic review [22] as being the most sensitive to exclude incomplete urine collection, but is likely nonetheless to have excluded considerably more individuals with complete than with incomplete urine collection [22]. We interpret the findings of these sensitivity analyses as suggesting that while bias in the mean estimates from the main sample is possible, correcting for this would not substantially affect our conclusions.

Measurement error in the assessment of dietary intake using 24-h recall may have occurred. However, the use of trained data collectors using food models and household measures to quantify portion size, would have reduced this potential limitation. We appreciate that the underlying USDA and Canadian food composition databases of Nutribase, may have not precisely captured the actual sodium content in the reported Barbadian foods, despite the addition of traditional Barbadian recipes to the database [24]. Most of the dietary recalls were recorded on week days (74\%) with all weekdays being evenly represented (11-14\%) except for Monday (22\%). This may have influenced our findings.

Globally, most countries have adopted a multifaceted approach towards strategies for salt reduction. Food reformulation, consumer education, front of pack labelling (FoPL), interventions in public institution settings (such as schools, hospitals and the workplace) and taxation have been pursued [35]. The most frequently used FoPL schemes are logos and symbols, which also include traffic light style labels, to indicate whether the product meets established nutrient criteria [36]. The $36 \%$ reduction in population salt intake achieved in Finland since 1993 is partially attributed to its mandatory warning labels on high salt foods. This in turn led to a significant reformulation of high sodium foods [37, 38]. To date however only two developing countries, South Africa and Argentina, have adopted comprehensive legislative schemes to limit the salt content in foods [39, 40].The main contributors to sodium intake in our study, any bread (9.2\%), rice and peas (6.2\%), baked chicken (4.9\%), macaroni pie (4.3\%) and white rice (4.3\%), were similar for both sexes. These foods contain sodium mainly added during the cooking process making them sodium dense foods (Table 7 in Appendix). Through public health promotion and education changes in food preparation practices can be achieved [41].

For Barbados to reach recommended WHO and AHA daily targets, potassium excretion would need to double and sodium excretion to decrease by one-third. We have identified the main dietary sources of sodium which could be used as potential targets, in a future population-wide salt reduction campaign. Future qualitative research is warranted to explore the drivers and barriers towards food preferences. A combined effort involving both individual and societal interventions will be needed to address these dietary imbalances and to reduce the high levels of obesity and physical inactivity [42] for this population at high risk of CVD.

\section{Conclusions}

This study, conducted in Barbados, is the first in the Caribbean to provide an objective assessment of sodium and potassium excretion. In this population at high risk of hypertension, sodium excretion was high and potassium excretion low, across all age, sex and educational strata. These findings provide baseline metrics which can be used for designing and evaluating dietary interventions targeted to reduce the risk of hypertension in this and similar populations. 


\section{Appendix}

Table 5 24-h urinary sodium and potassium excretion, and sodium-to-potassium ratio, by age and sex: restricted to those with greater or equal to $4 \mathrm{mmol} / \mathrm{d}$ (women) and $6 \mathrm{mmol} / \mathrm{d}(\mathrm{men})$ creatinine in their urine $(\mathrm{n}=317)$. Figures are means with $95 \%$ confidence intervals $(95 \% \mathrm{Cl})$

\begin{tabular}{|c|c|c|c|}
\hline & Sodium (mg) & Potassium (mg) & Sodium/potassium \\
\hline \multicolumn{4}{|l|}{ Women } \\
\hline $25-44$ years & $2623.1(2227.8,3018.3)$ & $1279.5(1143.7,1415.3)$ & $2.1(1.9,2.3)$ \\
\hline $45-64$ years & $2472.2(2222.4,2722.1)$ & $1594.0(1422.2,1765.9)$ & $1.7(1.5,1.9)$ \\
\hline Total & $2555.1(2275.4,2834.8)$ & $1421.2(1296.9,1545.4)$ & $1.9(1.8,2.1)$ \\
\hline \multicolumn{4}{|l|}{ Men } \\
\hline $25-44$ years & $3044.8(2747.3,3342.3)$ & $1548.2(1401.8,1694.7)$ & $2.1(1.9,2.3)$ \\
\hline 45-64 years & $2785.1(2511.6,3058.7)$ & $1639.4(1450.8,1827.9)$ & $2.0(1.6,2.3)$ \\
\hline Total & $2924.8(2718.0,3131.7)$ & $1590.3(1474.1,1706.5)$ & $2.1(1.9,2.2)$ \\
\hline \multicolumn{4}{|c|}{ Men and women } \\
\hline 25-44 years & $2827.2(2586.2,3068.2)$ & $1409.5(1309.0,1510.1)$ & $2.1(2.0,2.3)$ \\
\hline 45-64 years & $2627.3(2447.0,2807.6)$ & $1616.5(1489.7,1743.2)$ & $1.8(1.6,2.0)$ \\
\hline Total & $2736.0(2572.2,2899.8)$ & $1503.9(1427.5,1580.4)$ & $2.0(1.9,2.1)$ \\
\hline
\end{tabular}

Table 6 24-h urinary sodium and potassium excretion, and sodium-to-potassium ratio, by age and sex, restricted to those with $\geq 0.7$ of predicted sex specific creatinine excretion per kg body weight $(n=184)$

\begin{tabular}{lllr}
\hline & Sodium $(\mathrm{mg})$ & Potassium $(\mathrm{mg})$ & Sodium/potassium \\
\hline $\begin{array}{l}\text { Women } \\
\text { 25-44 years }\end{array}$ & $3137(2433,3841)$ & $1416(1180,1652)$ & $2.3(1.9,2.7)$ \\
$45-64$ years & $2316(1993,2638)$ & $1631(1344,1918)$ & $1.6(1.3,1.9)$ \\
Total & $2735(2301,3169)$ & $1521(1317,1725)$ & $2.0(1.7,2.2)$ \\
Men & & & $2.2(1.9,2.4)$ \\
$25-44$ years & $3130.1(2797,3464)$ & $1569.7(1430,1709)$ & $1.9(1.6,2.3)$ \\
$45-64$ years & $2800.1(2546,3054)$ & $1651.0(1438,1864)$ & $2.1(1.9,2.2)$ \\
Total & $2987.6(2760,3215)$ & $1604.8(1489,1721)$ & $2.2(2.0,2.4)$ \\
Men and women & & $1512(1400,1624)$ & $1.8(1.5,2.0)$ \\
$25-44$ years & $3133(2797,3468)$ & $1642(1471,1813)$ & $2.0(1.8,2.2)$ \\
$45-64$ years & $2592(2388,2795)$ & $1571(1473,1670)$ & \\
Total & $2887(2673,3100)$ & & \\
\hline
\end{tabular}

Figures are means with $95 \%$ confidence intervals $(95 \% \mathrm{Cl})$

Table 7 Percentage contribution of the top three individual foods within each of the top 10 food groups in Barbados (2012-2013)

\begin{tabular}{|c|c|c|c|}
\hline Food group & Food item & Proportion \% & Sodium density $(\mathrm{mg} / 100 \mathrm{~g})$ \\
\hline \multirow[t]{3}{*}{ Poultry } & Baked chicken & 37.8 & 251 \\
\hline & Fried chicken & 26.4 & 510 \\
\hline & Chicken roti & 14.1 & 287 \\
\hline \multirow[t]{3}{*}{ Rice } & Rice and peas & 46.4 & 190 \\
\hline & White rice & 31.8 & 382 \\
\hline & Vegetable rice & 9.7 & 251 \\
\hline \multirow[t]{3}{*}{ Bread } & White/whole wheat ${ }^{a}$ & 30.4 & 511 \\
\hline & Bakes & 13.0 & 723 \\
\hline & Bran & 13.1 & 472 \\
\hline
\end{tabular}


Table 7 Percentage contribution of the top three individual foods within each of the top 10 food groups in Barbados (2012-2013) (Continued)

\begin{tabular}{|c|c|c|c|}
\hline Food group & Food item & Proportion \% & Sodium density $(\mathrm{mg} / 100 \mathrm{~g})$ \\
\hline \multirow[t]{3}{*}{ Fish } & Fried fish & 45.3 & 469 \\
\hline & Fish, in oil & 21.8 & 396 \\
\hline & Stewed/steamed & 14.8 & 717 \\
\hline \multirow[t]{3}{*}{ Processed meats } & Hotdog & 30.5 & 684 \\
\hline & Ham & 19.5 & 1038 \\
\hline & Luncheon meat & 17.1 & 820 \\
\hline \multirow[t]{3}{*}{ Cakes, sweet breads } & Coconut bread & 54.6 & 752 \\
\hline & Cake-Bajan Pudding & 15.15 .3 & 403 \\
\hline & Chocolate cake & & 334 \\
\hline \multirow[t]{3}{*}{ Pasta } & Macaroni Pie & 79.0 & 293 \\
\hline & Chow Mein & 6.2 & 439 \\
\hline & Macaroni and cheese & 4.2 & 336 \\
\hline \multirow[t]{3}{*}{ Vegetables } & Mixed with salt & 31.3 & 271 \\
\hline & Pickled cucumber & 17.77 .6 & 1208 \\
\hline & Coleslaw & & 270 \\
\hline \multirow[t]{3}{*}{ Ground provisions } & French fries/wedges & 37.6 & 757 \\
\hline & English potato & 31.9 & 333 \\
\hline & Mashed/boiled Coucou & 9.7 & 196 \\
\hline \multirow[t]{3}{*}{ Red meat } & Beef stew & 22.4 & 480 \\
\hline & Lamb stew & 17.6 & 496 \\
\hline & Ground beef & 12.5 & 576 \\
\hline
\end{tabular}

Whole wheat and white bread contributed the same proportion of sodium within the bread category

\section{Abbreviations}

AHA: American Heart Association; BMl: Body mass index; BP: Blood pressure Cl: Confidence interval; CVD: Cardiovascular disease; FoPL: Front of packet labelling; HotN: Health of the Nation study; K: Potassium; Na:K: Sodium-topotassium ratio; Na: Sodium; NCDs: Non-communicable diseases; PAHO: Pan American Health Organization; USDA: United States Department of

Agriculture; WHO: World Health Organization

\section{Acknowledgements}

The authors wish to acknowledge all study participants, without whom we would not have been able to perform this study. Appreciation is extended to Professor Sir Trevor Hassell for initiating the study, Dr. Suzanne SoaresWynter and Dr. Kenneth Connell for expertise and guidance throughout the study, and the Ministry of Health, Barbados, for funding. We are grateful to Amy Browne and Clare Clouden for assistance with data collection.

\section{Funding}

The Ministry of Health of the Government of Barbados.

\section{Availability of data and materials}

The datasets generated during and/or analysed during the current study are available from the corresponding author on reasonable request.

\section{Author's contributions}

$\mathrm{RMH}, \mathrm{AMCR}, \mathrm{IRH}, \mathrm{CH}, \mathrm{NGF}, \mathrm{AJH}$ and $\mathrm{NU}$ designed the study; RMH provided essential nutritional coding for dietary data; IRH provided statistical guidance for this study; AMCR, RMH and NU performed the statistical analysis; NGF and TAS provided their expertise during the final stages of this study; $\mathrm{RMH}$ and NU produced the first article draft. All authors read, reviewed, and approved the final manuscript.

\section{Ethics approval and consent to participate}

All procedures followed were in accordance with the Helsinki Declaration of 1975 as revised in 1983, with ethical approval granted by the Institutional Review Board of the Ministry of Health, Barbados and the University of the West Indies. All participants provided written informed consent.

\section{Consent for publication}

Not applicable.

\section{Competing interests}

The authors declare that they have no competing interests.

Glossary: Description of some commonly consumed traditional composite dishes and foods in Barbados

Bakes

A flour-based dumpling, which is shallow-fried in oil. Usually eaten as a breakfast item or snack, with fish cakes or on their own.

Chicken and potato roti

Chicken and potato curry wrapped in a roti skin and eaten as a meal. Coconut bread

Dense cake made with grated coconut, vanilla essence and dried fruit (raisins, cherries). This is a traditional Barbadian delicacy Coucou

Part of the National dish made from ground corn (cornmeal) and boiled okras, cooked into a firm paste. Usually served with steamed fish and frizzled salt fish

Ground provisions

Name given in the Caribbean to tubular root vegetables which are encased in the ground during growth; such as sweet potatoes, cassava (yucca), eddoes, tania and yams. Plantains, green bananas, corn and breadfruit, although not grown in the ground, are also considered to 
be ground provisions because they are often cooked with tubular root vegetables. Ground provisions are served as the main carbohydrate of the meal or as a side dish

Macaroni pie

Baked dish of macaroni mixed with a seasoned cheese-based sauce, a popular Barbadian starchy food dish

Minced meat

Sautéed ground beef, seasoned with onions, tomatoes and herbs. May be served with macaroni, chow mien or rice as part of a main meal

Peas and rice

A mixed dish of dried or fresh legumes (kidney beans, lentils, black-eye peas) and parboiled rice. Boiled in salted water seasoned with onion and herbs until dry. Salted cured meat may also be added during boiling. This dish is a staple in the Barbadian diet

Vegetable rice

A mixture of seasonal vegetables, most commonly carrots, beans or spinach, cooked with parboiled rice to form this composite dish. It is eaten as a starchy food.

\section{Publisher's Note}

Springer Nature remains neutral with regard to jurisdictional claims in published maps and institutional affiliations.

\section{Author details}

${ }^{1}$ The George Alleyne Chronic Disease Research Centre, Caribbean Institute for Health Research, The University of the West Indies, Bridgetown, Barbados. ${ }^{2}$ MRC Epidemiology Unit, University of Cambridge, Cambridge, UK.

Received: 25 April 2018 Accepted: 11 June 2018

Published online: 09 August 2018

\section{References}

1. Brown IJ, Tzoulaki I, Candeias V, Elliot P. Salt excretions around the world: implications for public health international. J Epidemiol. 2009;38:791-813.

2. Webster JL, Dunford EK, Neal BC. A systematic survey of the sodium contents of processed foods. Am J ClinNutr. 2010;91(2):413-20.

3. World Health Organization. Global action plan for the prevention and control of noncommunicable diseases 2013-2020. Geneva: World Health Organization; 2013.

4. World Health Organization. Global Strategy on Diet, Phys Act Health: Population Sodium Reduction Strategies. Available online: http://www.who. int/dietphysicalactivity/reducingsalt/en/ (Accessed 12 Dec 2013).

5. Appel LJ, Frohlich ED, Hall Jem Pearson TA, Sacco RL, Seals DR, Sacks FM, Smith SC Jr, Vafiadis DK, Van Horn LV. The importance of population-wide sodium reduction as a means to prevent cardiovascular disease and stroke: a call to action from the American Heart Association. Circulation 2011;123: 1138-1143.

6. Yang Q, Liu T, Kuklina EV, Flanders WD, Hong Y, Gillespie C, Chang MH, Gwinn M, Dowling N, Khoury MJ, et al. Sodium and potassium intake and mortality among US adults: prospective data from the third National Health and nutrition examination survey. Arch Intern Med. 2011;171:1183-91.

7. Barbados Statistical service. Barbados population and housing census. 2010 (cited 27 November 2014) http://www.barstats.gov.bb/files/documents/ PHC_2010_Census_Volume_1.pdf

8. Howitt C, Hambleton IR, Rose AMC, Hennis AJM, Samuels TA, George KS, Unwin N. Social distribution of diabetes, hypertension and related risk factors in Barbados: a cross-sectional study. BMJ Open. 2015;5:e008869. https://doi.org/10.1136/bmjopen-2015-008869.

9. World Health Organization. Noncommunicable diseases country profiles 2011. Geneva, Switzerland: World Health Organization,2011 (cited 28 November 2014). http://www.who.int/nmh/publications/ncd_profiles report.pdf

10. WHO/PAHO Regional Expert Group for Cardiovascular Disease Prevention through Population-wide Dietary Salt Reduction. Protocol for Population Level Sodium Determination in 24-hour Urine Samples. http://new.paho. org/hq/dmdocuments/2010/pahosaltprotocol.pdf . Published May 2010.

11. World Health Organization. Reducing salt intake in populations: report of a WHO form and technical meeting. Paris: WHO; 2007. p. 1-60.

12. Cogswell ME, Loria CM, Terry AL, et al. Estimated 24-hour urinary sodium and potassium excretion in US adults. JAMA. 2018;319(12):1209-20. https:// doi.org/10.1001/jama.2018.1156.
13. Bingham SA. Biomarkers in nutritional epidemiology. Public Health Nutr 2002:5(6A):821-7.

14. Grim CE, Wilson TW, Nicholson GD, Hassell TA, Fraser HS, Grim CM, Wilson DM. Blood pressure in blacks. Twin studies in Barbados. Hypertension. 1990; 15(6 Pt 2):803-9.

15. Cooper R, Rotimi C, Ataman S, McGee D, Osotimehin B, Kadiri S, Muna W, Kingue S, Fraser H, Forrester T, Bennett F, Wilks R. The prevalence of hypertension in seven populations of west African origin. Am J Public Health. 1997:87(2):160-8.

16. Powles J, Fahimi S, Micha R, Khatibzadeh S, Shi P, Ezzati M, Engell RE, Lim SS, Danaei G, Mozaffarian D, on behalf of the Global Burden of Diseases Nutrition and Chronic Diseases Expert Group (NutriCoDE). Global, regional and national sodium intakes in 1990 and 2010: a systematic analysis of 24 h urinary sodium excretion and dietary surveys worldwide. BMJ Open 2013;3: 12 e003733. https://doi.org/10.1136/bmjopen-2013-003733

17. Elliot P, Brown I. Sodium intakes around the world. Geneva: World Health Organization; 2007.

18. INTERSALT Cooperative research group. Intersalt: an international study of electrolyte excretion and blood pressure. Results for 24-hour urinary sodium and potassium excretion. Brit Med J. 1988;297:319-28.

19. Charlton K, Ware L, Menyanu E, Biritwum R, Naidoo N, Pieterse C, Madurai S, Baumgartner J, Asare G, Thiele E, et al. Leveraging ongoing health research to evaluate the health impacts of South Africa's salt reduction strategy: a prospective nested cohort within the WHO-SAGE multicountry, longitudinal study. BMJ Open. 2016;6:e013316. https://doi. org/10.1136/bmjopen-2016-013316.

20. Stolarz-Skrzypek K, Kuznetsova T, Thijs L, Tikhonoff V, Seidlerová J, Richart T, Jin Y, Olszanecka A, Malyutina S, Casiglia E, et al. Fatal and nonfatal outcomes, incidence of hypertension, and blood pressure changes in relation to urinary sodium excretion. JAMA. 2011:305:1777-85.

21. Joossens JV, Geboers J. Monitoring salt intake of the population: methodological considerations. In: De Backer GG, Pedoe HT, Ducimetiere $P$, editors. Surveillance of the dietary habits of the population with regard to cardiovascular diseases, EURONUT report 2. Wageningen: Department of Human Nutrition, agricultural university; 1984. p. 61-73.

22. John KA, Cogswell ME, Campbell NR, Nowson CA, Legetic B, Hennis AJ, Patel SM. Accuracy and usefulness of selected methods for assessing complete collection of 24-hour urine: a systematic review. J ClinHypertens (Greenwich). 2016;18(5):456-67. https://doi.org/10.1111/jch.12763. Epub 2016 Jan 3

23. Raper N, Perloff B, Ingwersen L, Steinfeldt L, Anand J. An overview of USDA's dietary intake data system. J Food Compos Anal. 2004;17: 545-55.

24. Sharma S, Harris R, Cao X, Hennis AJ, Leske MC, Wu SY, Barbados National Cancer Study Group. Nutritional composition of the commonly consumed composite dishes for the Barbados national Cancer study. Int J Food Sci Nutr. 2007:58(6):461-74.

25. Sharma S, Cao X, Harris R, Hennis AJ, Wu SY, Leske MC. Assessing dietary patterns in Barbados highlights the need for nutritional intervention to reduce risk of chronic disease; Barbados National Cancer Study Group. J Hum Nutr Diet. 2008;21(2):150-8. https://doi.org/10.1111/j.1365-277X.2008.00858.x.

26. Lloyd-Jones DM, Hong Y, Labarthe D, Mozzaffarian D, Appel LJ, Van Horn L, Greenlund K, Daniels S, Nichol G, Tomaselli GF, et al. Defining and setting national goals for cardiovascular health promotion and disease reduction, the American Heart Association's strategic impact goal through 2020 and beyond. Circulation. 2010;121:586-613.

27. WHO. Sodium intake for adults and children. 2012 http://www.who.int/ nutrition/publications/guidelines/sodium intake/en/.

28. Androgue HJ, Madias NE. The impact of sodium and potassium on hypertension risk. SeninNephrol. 2014;34(3):257-72.

29. Maldonado-Martin A, Garcia-Matarin L, Gil-Extremera B, Avivar-Oyonarte C, Garcia-Granados ME, Gil-Garcia F, Latorre-Hernández J, Miró-Gutiérrez J, Soria-Bonilla A, Vergara-Martín J, et al. Blood pressure and urinary excretion of electrolytes in Spanish schoolchildren. J Hum Hypertens. 2002;16(7):473-8.

30. Swanepoel B, Schutte AE, Cockeran M, Steyn K, Wentzel-Viljoen E. Sodium and potassium intake in South Africa: an evaluation of 24-hour urine collections in a white, black, and Indian population. J Am SocHypertens. 2016;10(11):829-37. https://doi.org/10.1016/j.jash.2016.08.007.

31. Yan L, Guo X, Wang H, Zhang J, Tang J, Lu Z, Cai X, Liu L, Gracely EJ, Ma J. Population-based association between urinary excretion of sodium, 
potassium and its ratio with albuminuria in Chinese. Asia Pac J ClinNutr. 2016;25(4):785-97. https://doi.org/10.6133/apjcn.092015.33.

32. INTERSALT Cooperative research group. Intersalt: an international study of electrolyte excretion and blood pressure. Results for 24-h urinary sodium and potassium excretion. Brit Med J. 1988;297:319-28.

33. Stamler J, Elliot P, Dennis B, Dyer AR, Kesteloot H, Liu K, Ueshima H, Zhou BF. INTERMAP: Background, aims, design, methods, and descriptive statistics (non-dietary). J Hum Hypertens. 2003;17:591-608.

34. Bingham SA, Cummings JH. The use of creatinine output as a check on the completeness of 24-hour urine collections. Hum NutrClinNutr. 1985;39(5):343-53.

35. World Health Organization. Mapping salt reduction initiatives in the WHO European Region Copenhagen: WHO Regional Office for Europe; 2013. [cited 201329 October]. http://www.euro.who.int/_data/assets/pdf_file/ 0009/186462/Mapping-salt-reduction-initiatives-in-the-WHO-EuropeanRegion.pdf.

36. World Health Organization. Creating an enabling environment for population based salt strategies. Switzerland 2010 [citied 201430 October]. http://whqlibdoc.who.int/publications/2010/9789241500777_eng.pdf.

37. Pietinen P, Valsta LM, Hirvonen T, Sinkko H. Labelling the salt content in foods: a useful tool in reducing sodium intake in Finland. Public Health Nutr. 2008. April;11(4):335-40.

38. Trieu K, Neal B, Hawkes C, Dunford E, Campbell N, Rodriguez-Fernandez R, Legetic B, McLaren L, Barberio A, Webster J. Salt reduction initiatives around the world - a systematic review of progress towards the global target. PLoS One. 2015;10(7):e0130247. https://doi.org/10.1371/journal.pone.0130247.

39. South Africa Government. Government Gazette: NO. R. 214 Foodstuffs, Cosmetics and Disinfectants Act, 1972 (Act 54 of 1972) Regulations Relating to the Reduction of Sodium in Certain Foodstuffs and Related Matters. Heart Foundation; 2013 [cited 20147 April]. http://extwprlegs1.fao.org/docs/ pdf/saf122848.pdf.

40. Ministerio de Salud. ALIMENTOS Ley 26.905 Consumo de sodio. ValoresMáximos: Ministerio de Salud; 2014. [cited 20148 May]. http://www.msal.gov.ar/ent/ images/stories/programas/pdf/2014-08_Ley26905-Ley-Sodio.pdf.

41. Park S, Lee H, Seo DI, Oh KH, Hwang TG, Choi BY. Educating restaurant owners and cooks to lower their own sodium intake is a potential strategy for reducing the sodium contents of restaurant foods: a small-scale pilot study in South Korea. Nutr Res Pract. 2016;10(6):635-40. Epub 2016 Nov 10

42. Howitt C, Brage S, Hambleton IR, Westgate K, Samuels TA, Rose AM, Unwin N. A cross-sectional study of physical activity and sedentary behaviours in a Caribbean population: combining objective and questionnaire data to guide future interventions. BMC Public Health. 2016;16(1):1036.

\section{Ready to submit your research? Choose BMC and benefit from:}

- fast, convenient online submission

- thorough peer review by experienced researchers in your field

- rapid publication on acceptance

- support for research data, including large and complex data types

- gold Open Access which fosters wider collaboration and increased citations - maximum visibility for your research: over $100 \mathrm{M}$ website views per year

At BMC, research is always in progress.

Learn more biomedcentral.com/submissions 